\title{
Practice and Exploration of Teaching Mode in Power Electronic Technology Based on Project Driving Teaching
}

\author{
Lei, Shi \\ College of Engineering, Bohai University, Jinzhou 121000, China \\ email: shileiboda@163.com
}

Keywords: Project Driving Teaching; Power Electronic Technology; Teaching model; Practice

\begin{abstract}
Project Driving Teaching (PDT) was one of the effective ways in implementing "Inquiry Teaching Model”, so Project Driving Teaching was introduced in Power Electronic Technology which was the core technical course of automation technology specialized subject, and the circulation teaching model of "perception-learning-application-summary-improvement" was set up in order to develop the students' ability to discover, analysis and solve the problems. Finally the practice had proved that Project Driving Teaching not only helped to improve classroom efficiency and students' learning motivation, but also helped to train the consciousness of innovation and team cooperation.
\end{abstract}

\section{Introduction}

It was particularly important to train the consciousness of innovation and practice ability in teaching process of Power Electronic Technology which was the core curriculum of strong electricity specialty[1]. And its purpose was to improve students' abilities of designing power electronics products using basic theory and professional knowledge and effective solutions to practical problems in engineering and train students' engineering practice ability and compound quality including in the three respects: engineering quality, innovation ability and practice ability. Of those the engineering quality was done by theory teaching including basic course teaching, specialty teaching, curriculum design and graduation project etc. and the innovation ability and practice ability was done by practice teaching including various internships, Undergraduates Electronic Design Competition, Mechanical Innovative Design Competition[2], Undergraduate Innovative Experiment Project and teachers' research projects etc. However the traditional force-feeding method focusing on theories knowledge by centralism teaching and evaluating the learning effect by exams neglected ability development and led to students 'lack of enthusiasm and positivity. Accordingly, a new teaching mode in power electronic technology based on Project Driving Teaching was explored and researched.

Project driven, also known as task driven, goal driven and problem driven was one of the effective ways in implementing "Inquiry Teaching Model" taking project as a carrier, taking students as major part and leading by teachers[3]. Specifically, the core concepts and principles of a certain course were reflected through one or more projects in order to help the students to obtain the relating knowledge during completing these project independently, improve classroom efficiency and students' learning motivation[4], and train the consciousness of innovation and team cooperation. Thus it was a new learning method for students as well as a new teaching method for 
teachers.

Power Electronic Technology was the core curriculum of strong electricity specialty with strong practicality and comprehensiveness which was very suitable for Project Driving Teaching method[5].

\section{Applying Project Driving Teaching}

By Project Driving Teaching, the project was carefully designed and chosen from the principle of Project Driving Teaching with emphasis on guidance step by step aim to improve students ' innovative consciousness and cultivate students ' research ability.

\section{Selection}

It was especially important to select a right project successfully which could directly affect the teaching effectiveness according to three factors - feasible, moderate and representative.

\section{Analysis and completion}

Analysis and completion was the key[6]. First of all, the project tasks should be fully discussed and analyzed by students in order to find the key issues, key technologies, implicit new knowledge points, difficulties and feasibilities during project completion. Then according to the actual situation, the students were divided specifically in groups to explore and solve problems using different methods and paths, during which, the students cooperated with each other for the comprehension and application of professional knowledge collectively. Further, the students would be properly guided to self-study by tasks constantly and access to information depending on the requirements in order to transform passivity into initiative and change from have learned to manage to learn. To be clear, students were a main body and teacher were only a guider in the process.

3. Evaluation and assessment

After project completion, the performance including group one and individual one would be assessed based on the results such as models, reports and demonstrations etc. by experts, teachers and other students who were related to the specialty which were different from the traditional mode of taking examination. Special instruction: the assessment would include not only the results but also the learning process.

\section{Application in Power Electronic Technology}

Power Electronic Technology was the core curriculum of strong electricity specialty which played a connecting role in the course system. Following Project Driving Teaching, its teaching content was divided into five modules: dimming lamp, three-phase full bridge controlled rectifier, switching power supply, medium frequency induction heating power supply and frequency converter, each of which was subdivided into small modules on the basis of actual need[7]. Then the teacher arranged tasks according to students 'cognitive level from easy to difficult.

Taking "dimming lamp” as an example, this module fused the knowledge of thyristor, unijunction transistor[8], Single-Phase rectifier circuit and the phase shift trigger circuit with single junction transistor etc. with the specific teaching process as shown in Figure 1.

1. Determining task

The ordinary lamps could not adjust the lighting, so the students needed to analyses and design a adjustable circuit on the basis of the knowledge of rectifier circuit using power electronic devices such as thyristor and unijunction transistor etc. but adjustable resistor. 


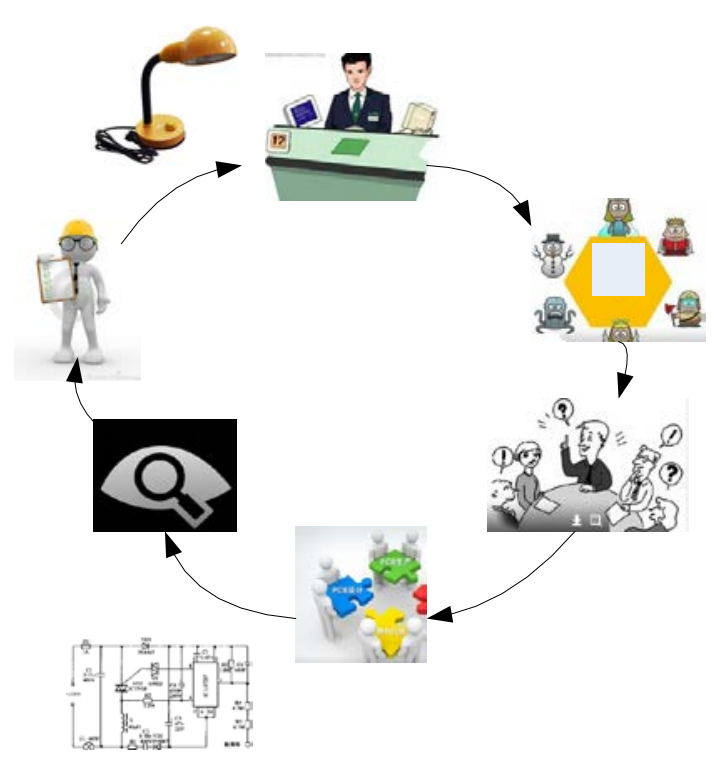

Figure 1 The flow chart of Project Driving Teaching

\section{Making plan}

The students were arranged as 5 per group to select team heads as project manager, and then collected and analyzed the information specially to draw up a design program independently which included work steps, test methods and implementation plans. timely. Then the best solution was decided in panel discussion with the timely-guidance of teachers.

3. Starting plan

Firstly, depending on the project needs, the model of thyristors and other related devices were selected from various types of power electronic devices being mixed together by teacher deliberately through which the students' recognition degree could be tested. Secondly, the students welded the components according to the circuit diagram for debugging, during which there might be various problems such as wrong pin positions, wrong element polarities, false welding and line short etc. If the problems could not be effectively solved by students, the teacher should guide them timely to strengthen their confidence. And after finishing the dimming lamp, the students needed to observe the trigger circuit waveform and the voltage waveform of rectified circuit using oscilloscope, analyze the working principles and master the analytical methods. To be sure, the students should be guided heuristically in accordance with their aptitude for training their thinking and innovative abilities.

4. Checking project

During the implementation of the project, there would be self-inspection by the students and assistant inspection by the teachers[9] to prevent diverting from the task. And after finishing the dimming lamp, there would be peer review to evaluate the accomplishments for training the students' responsibilities and quality consciousness.

\section{Evaluating project}

The evaluation contained the self-evaluation, the mutual-evaluation and the one evaluated by the teachers finally. Firstly, the self-evaluation included the summary of various aspects, for instance, the preparation, the solution of problems during the implementation process, the effects and the achievements etc. Secondly, the mutual-evaluation included the summary of the optimization, the results and component placement etc. Finally, the teacher gave a comment on the advantages and disadvantages each group, meanwhile, a final grade would be applied under the evaluation standard 
that the maximum mark was100, the self-evaluation accounted for $30 \%$, the mutual-evaluation accounted for $30 \%$ and the teacher evaluation accounted for $40 \%$.

\section{Conclusion}

Project Driving Teaching was introduced in Power Electronic Technology and the knowledge needed to master was converted to the practical project, which, could train the students' thinking, innovative abilities, responsibilities and quality consciousness. Furthermore, it sufficiently showed the value orientation aiming to developing students 'abilities. highlighted different characteristics of professional and vocational and followed the direction of industry and enterprise requirements which were compatible with the development model of technical abilities in order to lay the foundations for educating and cultivating high quality talents with technical skills.

\section{Acknowledgement}

In this paper, the research was sponsored by the Teaching Reform Project of Bohai University (Project No. BDJG-14-QN-C-006, BDJG-15-YB-C-008) and the National Natural Science Foundation (Project No. 11547180)

\section{Reference}

[1] Z.H.Qin,C.Deng. The practice and exploration of full English/bilingual teaching for Industrial Engineering majors. International Conference on Information Engineering and Education Science [C]. 2014.

[2] WANG Hua-ji.Practice and Exploration of the Dual-track Project Teaching Method in University Teaching. ICETMS [C]. 2013.

[3] Chunfang Wang,Limin Wang,Aidong Qian.Teaching Practice and Exploration of Animal Anatomy in Higher Agricultural University. 2nd International Conference on Communication Technology[C]. 2015.

[4] Liu Hong fu,Liang Shaohua. Practice and exploration of educational innovation in the teaching process of anatomy [J].Chongqing Medicine, 2012(25) 45-48.

[5] Zhang Yajuan, Liu Hanbing, Feng Lingxia. Teaching Practice And Exploration Of Compiler Principle Based On The Capability Cultivation For Application-Oriented Talents.2012 4th International Conference on Education Technology and Computer[C]. 2012.

[6] Huansong Yang. The Practice and Exploration of Using Blog in Chinese Writing Teaching of Junior Middle School. 2013 International Conference on Education and Teaching[C]. 2013.

[7] Qianzhao Lei. Practice and Exploration of Bilingual Teaching in Electromagnetism Classes. International Conference on Future Management Science and Engineering[C]. 2011.

[8] Y.P.Fan. Practice and Exploration of Social Demand-Oriented Higher Vocational EFL Teaching Reform. International Conference on Optics, Photonics and Energy Engineering[C]. 2010.

[9] Jiangfeng Li. Exploration of Teaching Practice On College Computer Basic Course Based on the Training of Information Literacy. The 2nd National Conference on Information Technology and Computer Science[C]. 2015. 